\title{
Soil carbon dynamic in public plantations and community planted forests in Terai, Nepal
}

\begin{abstract}
Terrestrial carbon plays a significant role in mitigation of climate change because it is the second largest store house of carbon. However soil carbon estimation is not common in the forests especially in plantation. Therefore, this study was objectively carried out to assess and compare the soil carbon in public plantation and community planted forests and show variation in soil carbon according to the soil depths. Six plantation areas were selected of Mahottary district. Total 52 sample plots were randomly established on the map of the plantation sites setting the complete random design. After that, the centre point coordinates of each sample plots were recorded and uploaded in GPS. Next, the sample plots were established in the field by navigating the coordinates. Altogether 156 soil samples were collected from three layers specifically $0-10,10-30$ and $30-60 \mathrm{~cm}$ using soil auger and analyzed in lab using the Walkley and Black method. The result showed that the highest soil carbon was found about 79.13 t ha-1 in Shreepur public plantation while it was the lowest about $15.44 \mathrm{t}$ ha-1 in Jogikuti community planted forest. The soil carbon was the highest in $0-10 \mathrm{~cm}$ depth, this was followed by soil carbon of $10-30 \mathrm{~cm}$ and least value was found in $30-60 \mathrm{~cm}$. In fact, the estimated records of soil carbon was the highest about $31.46 \mathrm{t}$ ha- 1 in Shreepur public plantation in $0-10 \mathrm{~cm}$ while it was the lowest about $3.45 \mathrm{t}$ ha- 1 in Jogikuti CPF in $30-60 \mathrm{~cm}$. In fact, soil carbon decreases according to increasing soil depth in a profile. The t-test showed that, there were significant differences in soil carbon of same aged plantations. The soil carbon stock was richer at plantation sites close to natural forest and edge of the pond in comparison to sites of river bank.
\end{abstract}

Volume 2 Issue 2 - 2017

\author{
Ram Asheshwar Mandal,' Ishwar Chandra \\ Dutta, ${ }^{2}$ Pramod Kumar Jha, ${ }^{3}$ Siddhi Bir \\ Karmacharya ${ }^{4}$ \\ 'REDD Implementation Centre, Babarmahal, Nepal \\ ${ }^{2}$ Chairman of Tribhuvan University Service Commission, Nepal \\ ${ }^{3} \mathrm{Head}$ of central department of Boatny Kirtipur, Nepal \\ ${ }^{4}$ Professor, Trichandra college, Nepal
}

\author{
Correspondence: Ram Asheshwar Mandal, REDD \\ Implementation Centre, Babarmahal, Kathmandu Nepal \\ Email ram.mandal@mail.com
}

Received: October 18, 2016 | Published: March 31, 2017

Keywords: public plantation, community planted forest, soil carbon dynamics

\section{Introduction}

The climate change is global burning issues which urgently need to address so that enable environment can be created to live on earth safely. In this context, the carbon removal from the atmosphere is recognized as important measures especially carbon sequestration by soil and vegetation. ${ }^{1}$ In fact, the soils perform a range of biological processes which assist to stabilize the atmospheric green house gases. ${ }^{2,3}$ Moreover, the soils represent the largest terrestrial stock of $\mathrm{C}$, holding approximately $1.5 \times 10^{15} \mathrm{gC}$ in the top one metre ${ }^{4}$ excluding. This is nearly twice the amount held in the atmosphere and three times the amount held in terrestrial vegetation. In addition, about $1 \%$ change in the amount of carbon stored in soils would equate near about 8ppm change in atmospheric $\mathrm{CO}_{2}$ concentration ${ }^{5,6}$ highlighted that the appropriate use and management of soil has the high potential to sequester approximately $0.9 \mathrm{PgC}$ annually. This is roughly equal to $13 \%$ of the anthropogenic $\mathrm{CO}_{2}-\mathrm{C}$ produced. Moreover, changing land use to forests and proper management practices can have additional environmental benefits. ${ }^{78}$ Therefore exploring $\mathrm{C}$ sequestration in soils is as a 'win-win' strategy ${ }^{9}$ for climate change perspective. The soil C losses can be mitigated by recarbonisation. ${ }^{10}$

Globally, anthropogenic carbon loss from terrestrial ecosystems including forests is estimated from 48 to $114 \mathrm{Pg}$ before the industrial revolution but since 1850 , another 108 to $188 \mathrm{Pg} \mathrm{C}$ has been lost, which mostly was vegetation biomass. ${ }^{11}$ Out of that about $25 \%$ of this loss was due to soil organic matter mineralization. ${ }^{11}$ The world's total forest area was estimated to be just over 4 billion hectares, corresponding to an average of 0.6 ha of forest per capita in 2010 . These forests store more than 650 billion tonnes of carbon, $44 \%$ in the biomass, $11 \%$ in dead wood and litter, and $45 \%$ in the soil. In Asia, the recorded carbon stock was 74453 million tonnes. Out of this, 35330 million tonnes store in soil. The average soil carbon was recorded 59.6t ha ${ }^{-1}$ in Asia. ${ }^{12}$ The estimated carbon stocks in primary forest were $337 \mathrm{t} \mathrm{ha}^{-1}$ than secondary forest $274 \mathrm{t} \mathrm{ha-113}$ in Singapore. The mean carbon stock was estimated $114 \pm 2.26 \mathrm{tha}^{-1}$ in managed forests, which comprises of $92 \%$ tree biomass and $8 \%$ of topsoil whereas it was $27.77 \pm 1.66 \mathrm{t} \mathrm{ha}^{-1}$ in unmanaged forests which comprises of $80.8 \%$ tree carbon and $19.2 \%$ soil carbon in Pakistan. ${ }^{14}$ These all forests have significant contribute to maintain soil carbon. There are huge gaps in study associated with the estimation of soil carbon especially in afforested areas. Particularly, assessment of soil carbon was not done in planted forests of Mahottary district before, though the public plantation and community planted forests have been storing considerable amount of carbon and playing a vital role. In addition, soil carbon varies according to soil layers. At the same time, the soil carbon varies in different sites even in same aged plantation. The soil carbon variation was also significantly noticed according to soil depths. Hence, this study was objectively carried out to assess and compare soil carbon of same aged plantations. The study also was emphasized to estimate the soil carbon in different layers.

Assessing the soil carbon is elevated interest to climate change arena and reducing deforestation and forest degradation (REDD + ) mechanism which consider this as a carbon credit. REDD + mechanism includes the forest enhancement, sustainable management of forests and forest conservation. ${ }^{15,16}$ This mechanism has been functioning for carbon trade but the technical preparations are mandatory to assess the carbon credit. The establishment of the reference level showing carbon stock and their dynamics as well as designation of 
monitoring reporting and verification (MRV) which includes the precise documentation of carbon estimation are technical aspects of this mechanism. It is the Copenhagen Accord which focused the interference with the global climate system as exceeding $2^{\circ} \mathrm{C}$ global mean temperature so it is more important to commit in order to stabilize the temperature not more than $-1.5^{\circ} \mathrm{C}$ in $21^{\text {st }}$ century. This decision was also supported by the 2015 Paris agreement. This implies the urgent need of emissions and removals estimates under the REDD+ mechanism. ${ }^{17}$ So, this study may help in development of technical parts at sub-national level REDD+ piloting.

\section{Methods}

\section{Research site}

Three of each public plantation and community planted forests of Mahottari district in central Tarai, Nepal were selected for study site (Figure 1). Mahottari district is situated in $26^{\circ} 36^{\prime}$ to $28^{\circ} 10^{\prime}$ North and $85^{\circ} 41^{\prime}$ to $85^{\circ} 57^{\prime}$ 'East. The average annual temperature ranges between $20-25^{\circ} \mathrm{C}$ and average annual rain fall recorded between 1100-3500 $\mathrm{mm}$. These studies sites were planted with pure Eucalyptus camaldulensis. The other natural species were Cynodon dactylon and Mimosa pudica. The selected public plantations were Shreepur, Banauta and Bisbitty while the community planted forests were Sita, Jogikuti and Ramnagar. In fact, the basic criteria of the selection of these plantaions were the age of the plantation (Table 1). The public plantation were established in three different years and managed by three different types of landless poor marginalized untouchable communities adopting diverse traditional jobs while community planted forests were managed by the nearest users. The public plantation of Shreepur was managed by Khatave- Mandal (sheep keeping community), plantation of Banauta was managed by Chamar community (shoe makers) and plantation of Bisbity was managed by Mushar community (soil worker). The inter crops were Lathyrus sativus, Aloe vera and green vegetables like Ladies finger, Cauliflower, Brinjal (Solanum malanga) of Bisbitty, Banauta and Shreepur public plantations respectively. However, there was no any agro-forestry work in community planted forests.

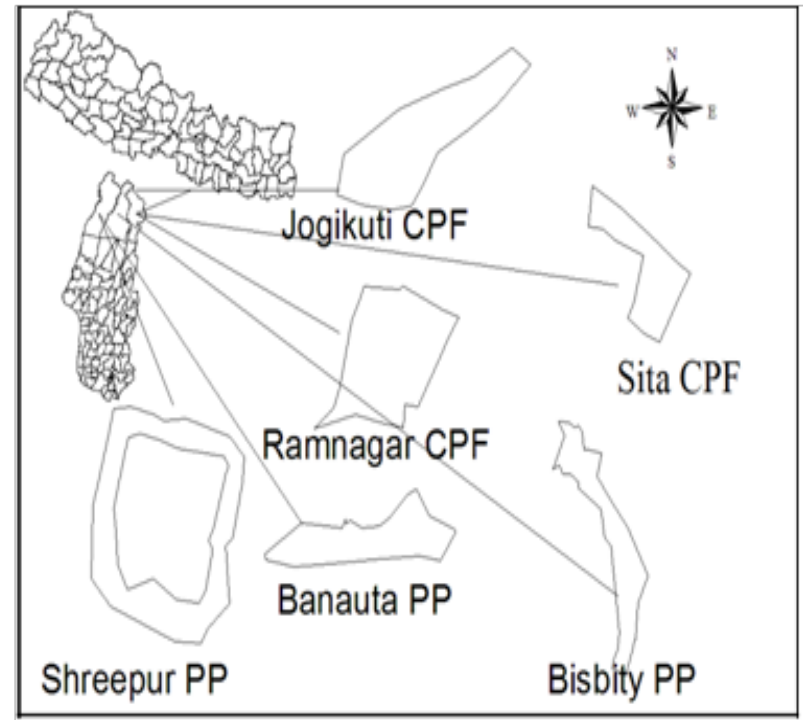

Figure I Maps of research areas.
Table I Study area

\begin{tabular}{lll}
\hline Community planted forests & Public plantation & $\begin{array}{l}\text { Plantation } \\
\text { year }\end{array}$ \\
\hline Bisbitty PP & Sita CPF & 2006 \\
Banauta PP & Jogikuti CPF & 2007 \\
Shreepur PP & Ramnagar CPF & 2008 \\
\hline
\end{tabular}

In order to conduct the sampling, first of all, the maps of these plantation areas were prepared using the coordinates taken by Geographical positioning system (GPS) with the help of ArcGIS 10 software. Then, simple random sampling was used maintaining $1 \%$ sample intensity ${ }^{18,19}$ setting the complete random experiment design (CRD). ${ }^{20}$ Altogether 28 sample plots were randomly distributed on the maps of public plantations (PPs) specifically 9, 11 and 8 plots for Banauta, Shreepur and Bisbity plantations respectively while 24 plots were on the community planted forests (CPFs) particularly 6, 7 and 11 plots for Sita, Jogikuti and Ramnagar respectively. After that, the centre point coordinates of each sample plots were recorded from the map and uploaded in GPS to navigate in the field.

\section{Data collection}

Soil samples were collected from three different layers specifically $0-10 \mathrm{~cm}, 10-3 \mathrm{ocm}$ and $30-6 \mathrm{~cm}$ using soil auger ${ }^{21,19}$ and packed in plastic to carry out in the lab for carbon analysis. So, altogether 156 soil samples collected in December to January, 2014.

\section{Soil carbon analysis}

Carbon content in the soil was analyzed by using dry combustion method. ${ }^{22}$

Bulk Density $(\mathrm{BDg} / \mathrm{cc})=($ oven dry weight of soil) $/($ volume of soil in the core)

The detail method and calculation of SOC are described below. This includes the reagent used, process and calculation.

\section{Reagents used}

Following reagents were used to prepare the chemical for soil carbon analysis.

Preparation of chemical for lab analysis for soil carbon

FAS $=$ Ferrous Ammonium Sulphate

$\mathrm{VF}=$ volumetric flask

AR grade=standard grade suitable for use

$\mathrm{N}=$ Normal

Sodium Fluoride (NaF): AR grade sodium fluoride powdered was used.

Firstly, $1 \mathrm{~N} \mathrm{~K}_{2} \mathrm{Cr}_{2} \mathrm{O}_{7}$ Solution: 49.04gm of $\mathrm{K}_{2} \mathrm{Cr}_{2} \mathrm{O}_{7}$ was kept at $105^{\circ} \mathrm{C}$ in hot air oven for 1 hour. As it cools down, it was diluted to $1000 \mathrm{ml}$ volumetric flask (VF). Then, $0.5 \mathrm{~N}$ FAS (Ammonium ferrous sulphate): $196 \mathrm{gm}$ of FAS was dissolved in $800 \mathrm{ml}$ of distilled water and added $20 \mathrm{ml}$ of conc. Sulfuric acid, cooled and diluted to $1000 \mathrm{ml}$ volumetric flask. Diphenylamine Indicator: Approximately $0.5 \mathrm{gm}$ of diphenylamine was dissolved in $20 \mathrm{ml}$ of distilled water and added $100 \mathrm{ml}$ of concentrate (conc.) Sulfuric acid. 


\section{Procedure}

Soil sample was sieved in order to remove the stones and roots. For this, $1 \mathrm{gm}$ of $0.2 \mathrm{~mm}$ sieved sample was weighed and placed in $500 \mathrm{ml}$ conical flask. Then, $10 \mathrm{ml}$ of $1 \mathrm{~N} \mathrm{~K}_{2} \mathrm{Cr}_{2} \mathrm{O}_{7}$ solution and $20 \mathrm{ml}$ of conc $\mathrm{H}_{2} \mathrm{SO}_{4}$ was added and mixed with gentle rotation for one minute. Next, the mixture was heated at $150^{\circ} \mathrm{C}$ in hot oven for 30 minutes. Meanwhile, the blank was run in the same manner. After 30minutes $200 \mathrm{ml}$ of distilled water and $2 \mathrm{ml}$ of diphenylamine indicator was added in it and $0.2 \mathrm{gm}$ of $\mathrm{NaF}$ was also added. Later, the $\mathrm{K}_{2} \mathrm{Cr}_{2} \mathrm{O}_{7}$ left and the $0.5 \mathrm{~N}$ FAS solution was titrated from burette. Then the volume of FAS consumed for titration and the brilliant green end point was noted down.

\section{Calculation}

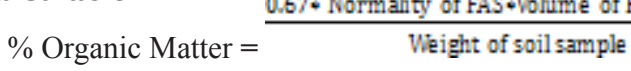

$$
\begin{aligned}
& \% \text { Organic Matter }=\frac{0.67 * \text { Normality of FAS *Volume of FAS consumed }}{\text { Weight of soil sample }}
\end{aligned}
$$

Where, Volume of FAS consumed= volume of FAS consumed by blank (chemical)- volume of FAS consumed by sample

When, molarity is converted into normality, 0.67 was used as a factor.

$$
\text { Normality of FAS }=\frac{\text { Volumeof potassium dichromatetakenen* Vormality of dichromate }}{\text { Volumeof FAS consumed byblank }}
$$

Normality of FAS $=$

Volume of potassium dichromate taken * Normality of dichromate

$$
\text { Volume of FAS consumed by blank }
$$

$$
\begin{aligned}
& \% \text { Organic Carbon }=\frac{\text { Soil organic matter }}{1.724} \\
& \% \text { Organic Carbon }=\frac{\text { Soil organic matter }}{1.724}
\end{aligned}
$$

Here, $58 \%$ soil organic matter $=100 \%$ organic carbon, 1.724 was used as a constant factor.

SOC $=$ Organic Carbon Content \% x Soil Bulk Density $(\mathrm{Kg} / \mathrm{cc}) \mathrm{x}$ thickness of horizon. ${ }^{22}$

\section{Statistical analysis}

The statistical comparison was carried out to compare the soil carbon using independent $t$-test ${ }^{23}$ using SPSS 20.

\section{Results and discussion}

\section{Total soil carbon in plantations}

Generally, the soil carbon stock was varied in the plantation areas according to locations. Total soil carbon was about 1965.44t in theses plantation sites. Out of them, the quantities of soil carbon were 79.13, 71.33, 37.00, 33.00, 16.74 and 15.44t ha $\mathrm{t}^{-1}$ in Shreepur PP, Sita CPF, Banauta PP, Ramnagar, Bisbitty PP and Jogikuti CPF respectively (Table 2). It was noticed that, the higher soil carbon in Sita CPF and Shreepur PP was because of fertile soil. Specifically, Sita CPF was located close to the natural forest and Shreepur PP was on the edge of the pond where soil fertility is very rich. However, the carbon stocks were low in Bisbity PP and Jogikuti CPF. Specifically, Banauta PP, Bisbitty PP, Ramnagar CPF and Jogukuti CPF are situated on the bank of the river where soil is sandy. The consequences were less organic matters and hence the soil had less carbon. It is fact that the organic carbon is added to soil through deposition in and on the soil of organic materials created by capturing $\mathrm{CO}_{2}$ through photosynthesis of vegetation. On the other hand, soil organic carbon is returned to the atmosphere as $\mathrm{CO}_{2}$ via respiration that occurs as soil organisms use organic materials as a source of energy and nutrients. ${ }^{24,25}$

Table 2 Carbon according to soil depth in public and community planted forests

\begin{tabular}{llll}
\hline Pp/Cpf & \multicolumn{3}{l}{ Depth wise soil carbon $\mathbf{t} \mathbf{h a}^{-\mathbf{1}}$} \\
\hline Layers & $0-10 \mathrm{~cm}$ & $10-30 \mathrm{~cm}$ & $30-60 \mathrm{~cm}$ \\
Shreepur PP & 31.46 & 29.39 & 18.28 \\
Banauta PP & 15.18 & 14.96 & 6.86 \\
Bisbitty PP & 7.96 & 5.04 & 3.74 \\
Sita CPF & 28.36 & 26.49 & 16.47 \\
Ramnagar CPF & 13.54 & 13.34 & 6.12 \\
Jogikuti CPF & 7.34 & 4.65 & 3.45 \\
\hline
\end{tabular}

The soil carbon was found to be $73.92 \mathrm{tha}^{-1}$ in Gorkhali leasehold forest (LHF), which value is quite similar to the value of Sita CPF. Similarly, the soil carbon of Ratmate leasehold forest was $37.89 \mathrm{t} \mathrm{ha}$ ${ }^{1,26}$ this value is close to the value of Banauta PP. The carbon stocks depend up on the stage of the plants, species of plantation, practices and silvicultural operations (agroforestry) adopted, site quality and microbial activities in the soil. ${ }^{27,28}$ The soil carbon of Tarai forest was reported 33.66 $\mathrm{tha}^{-1},{ }^{29}$ which is about to similar the record of soil carbon of Ramnagar CPF. The quantity of organic carbon contained in a soil is the direct result of the equilibrium between carbon inputs and losses. ${ }^{30}$

\section{Depth wise soil carbon}

As shown in Table 3, the soil carbon was the highest in $0-10 \mathrm{~cm}$ depth, this was followed by soil carbon of $10-30 \mathrm{~cm}$ and least value was found in $30-60 \mathrm{~cm}$. In fact, the estimated records of soil carbon were 31.46, 15.18, 7.96, 28.36, 13.54 and 7.34t ha ${ }^{-1}$ in Shreepur PP, Banauta PP, Bisbitty PP, Sita CPF, Ramnagar CPF and Jogikuti CPF respectively in $0-10 \mathrm{~cm}$. They were less $29.39,14.96,5.04,26.49$, 13.34 and 4.65t ha ${ }^{-1}$ in Shreepur PP, Banauta PP, Bisbitty PP, Sita $\mathrm{CPF}$, Ramnagar CPF and Jogikuti CPF respectively in 10-30 cm. Moreover, they were lower 18.28, 6.86, 3.74, 16.47, 6.12 and 3.45 $\mathrm{t} \mathrm{ha}^{-1}$ in Shreepur PP, Banauta PP, Bisbitty PP, Sita CPF, Ramnagar $\mathrm{CPF}$ and Jogikuti CPF respectively in $30-60 \mathrm{~cm}$ (Table 3). Clearly, soil carbon decreases according to increasing soil depth in a profile. This view is supported by other several studies. ${ }^{31-33}$ The soil carbon was 14.45 in Kalyankari LHF at $0-10 \mathrm{~cm}$ depth, ${ }^{26}$ which was matching with the soil carbon of Ramnagar CPF, the soil carbon of Sawunepani LHF was 13.54 at $10-30 \mathrm{~cm},{ }^{34}$ which is very close to the value of Ramnagar CPF.

\section{Comparison of soil carbon stock of same aged plantations}

The public plantation and community planted forests were afforested in the same year but carbon stocks showed some differences in these areas. Thus, they were statistically tested using the independent samples two tailed t-test statistics to compare the 
carbon stocks of these plantations. The t-test showed that, there were significant differences in carbon stocks between Banauta PP and Jogikuti CPF, Bisbitty PP and Sita CPF as well as Shreepur PP and Ramnagar $\mathrm{CPF}$ at $5 \%$ level of significance since the $\mathrm{p}$ values were less than 0.05 (Table 4).

Table 3 Soil Carbon in public plantations and community planted forests

\begin{tabular}{llll} 
Plantation & Area ha & Soil C t ha & Total soil carbon t ha-1 \\
\hline Shreepur PP & 10.5 & 79.13 & 830.87 \\
Banauta PP & 8.8 & 37 & 325.6 \\
Bisbitty PP & 7.6 & 16.74 & 127.22 \\
Sita CPF & 5.42 & 71.33 & 386.61 \\
Ramnagar CPF & 4.92 & 33 & 162.36 \\
Jogikuti CPF & 8.6 & 15.44 & 132.78 \\
Total & & & 1965.44
\end{tabular}

Table 4 Comparison of carbon stock between public plantation and community planted forests

\begin{tabular}{lllll}
\hline PP & CFP & $\begin{array}{l}\mathbf{t} \\
\text { calculated } \\
\text { value }\end{array}$ & $\begin{array}{l}\mathbf{t} \\
\text { tabulated } \\
\text { value }\end{array}$ & $\begin{array}{l}\mathbf{P}(\mathbf{T}<=\mathbf{t}) \\
\text { two-tail }\end{array}$ \\
\hline Banauta PP & Jogikuti CPF & -82.17 & 2.16 & 0 \\
Bisbitty PP & Sita CPF & -50.2 & 2.18 & 0 \\
Shreepur PP & Ramnagar CPF & 142.49 & 2.08 & 0 \\
\hline
\end{tabular}

\section{Conclusion and recommendation}

The soil carbon was the highest in plantation site close to the natural forest but it was the lowest in sites located to the river bank. The soil carbon was decreasing according to increasing depth of soil profile. Statistically, even in same aged two different plantations the quantities of soil was varied. There was slight variation in amount of soil carbon in $0-10$ and $10-30 \mathrm{~cm}$ soil depths but this was very low in $30-60 \mathrm{~cm}$ depth. It is recommended to assess soil carbon in plantation of different sites to create the data set to link with the REDD+ mechanism in Nepal.

\section{Acknowledgements}

None.

\section{Conflict of interest}

The author declares no conflict of interest.

\section{References}

1. Annemieke VW and Wietse B. Dinner in the dark: Illuminating drivers of soil organic matter decomposition. Soil Biology and Biochemistry. 2016;105(1):45-48.

2. Lal R. Soil carbon sequestration impacts on global climate change and food security. Science. 2004;304(5677):1623-1627.

3. Uroz S, Buee M, Deveau A, et al. Ecology of the forest microbiome: Highlights of temperate and boreal ecosystems. Soil Biology and Biochemistry. 2016;103(1):471-488.

4. Milne E. Soil organic carbon. Global Change Biology. 2012;3(2):161-173.
5. Baldock JA, Wheeler I, McKenzie N, et al. Soils and climate change: potential impacts on carbon stocks and greenhouse gas emissions, and future research for Australian agriculture. Crop and Pasture Science. 2012;63(3):269-283.

6. Lal R. Soil carbon sequestration to mitigate climate change. Geoderma. 2010;123(1):11-23.

7. Yadav JN, Manjan SK. Use of biological resources for reclamation of river damaged land, proceedings of national seminar on sustainable use of biological resources in Nepal. 2007:112-115.

8. Fraser FC, Todman LC, Corstanje R, et al. Distinct respiratory responses of soils to complex organic substrate are governed predominantly by soil architecture and its microbial community. Soil Biology and Biochemistry. 2016;103(1):493-501.

9. Batjes NH, Sombroek WG. Possibilities for carbon sequestration in tropical and sub-tropical soils. Global Change Biology. 2013;3(2):161-173.

10. Lorenz K, Lal R. Cropland soil carbon dynamics. In: Lal, R, et al. editors. Recarbonization of the Biosphere. Springer; 2012. p. 303-346.

11. Houghton R. Historic changes in terrestrial carbon storage. Recarbonization of the Biosphere. Springer; 2012. p. 59-82.

12. State of the World's Forests. Food and agriculture organization of the united Nations, Rome, Italy: FRA; 2011. 201 p.

13. Ngo KM, Turner B, Landau L, et al. Carbon stocks in primary and secondary tropical forests in Singapore. Forest Ecology and Management. 2013;29(6):81-89.

14. Nijami SM, Mirza SN, Livesley S, et al. Estimation carbon stock in sub tropical pine (Pinus roxburghii) forests of Pakistan. Pakistan Journal of Agriculture Sciennce. 2009;46(1):266-270.

15. Campbell BM. Beyond Copenhagen: REDD+agriculture, adaptation strategies and poverty. Global Environmental Change. 2009;19(4):397399.

16. Copenhagen Accord. Report of the Conference of the Parties on its fifteenth session. Held in Copenhagen from 7 to 19 December 2009, United Nations Framework Conventions on Climate Change; 2010. p. 76-87.

17. Barros Henrique S, Fearnside Philip M. Soil carbon stock changes due to edge effects in central Amazon forest fragments. Forest Ecology and Management. 2016;379(1):30-36.

18. Do F. Community forest resource inventory guideline, Department of Forests. Kathmandu, Nepal: Community Forests Division; 2003.

19. Kumar Amit, Sharma MP. Estimation of soil organic carbon in the forest catchment of two hydroelectric reservoirs in Uttarakhand, India. Human and Ecological Risk Assessment: An International Journal. 2015;53(1):112 .

20. Murray BC, McCarl BA, Lee H. Estimating leakage from forest carbon sequestration programs. Land Economics. 2004;80(1):109-124.

21. Wang XJ, Smethurst PJ, Herbert AM. Relationship between three measures of organic matter or carbon in soil of eucalypt plantations in Tasmania, Austrailia. Journal of Soil Resource. 1996;34:545-553.

22. Walkley AE, Black JA. An examination of the method for determining soil organic method, and proposed modification of the chromic acid titration method. Soil Science. 1958;37(1):29-38.

23. Gupta SC, Kapoor VK. Fundamentals of applied statistics. New Delhi: Sultan Chand and Sons 23 DaryGanj; 1984

24. Jia Juan, Feng Xiaojuan, He Jin-Sheng, et al. Comparing microbial carbon sequestration and priming in the subsoil versus topsoil of a Qinghai-Tibetan alpine grassland. Soil Biology and Biochemistry. 2016;104(1):141-151. 
25. Xiaoping Guo, Miaojing Meng, Jinchi Zhang, et al. Vegetation change impacts on soil organic carbon chemical composition in subtropical forests. Scientific Report. 2016;6:1-9.

26. Lama TD. Assessment of carbon sequestration potential of leasehold forests: a study of Katakuti VDC, Dolakha District. College of Applied Science. Tribhuwan Univeristy; Nepal: 2012.

27. Mini ER, Rao YS. An evaluation of soil carbon sequestration in teak and ecalypt plantations. Ne BIO. 2011;2(3):9-11.

28. Oren R, Ellsworth D, Johnsen K, et al. Soil fertility limits carbon sequestration by forest ecosystems in a $\mathrm{CO} 2$-enriched atmosphere. Nature. 2001;411(1):469-472.

29. FRA/DFRS. Tarai forests of Nepal (2010-2012) Babarmahal, Kathmandu. Forest resource assessment Nepal Project/Department of forest research and survey; 2014. $160 \mathrm{p}$.

30. Klein T, Siegwolf RTW, Korner C. Belowground carbon trade among tall trees in a temperate forest. Science. 2016;352(1):342-344.
31. Shrestha BM, Singh BR. Soil and vegetation carbon pools in a mountainous watershed of Nepal. Nutrient Cycle Agro-ecosystem . 2008;81(1):179-191.

32. Dutta IC, Mandal RA. Assessment of carbon sequestration on riverbank plantation (a case study of community forest in Mahottari District), proceeding a national conference on forest-people interaction; Institute of forestry, Pokhara and department of forest research and survey. 2009; 2010. p. 239-250

33. Harrison RB, Footen PW, Strahm BD. Deep soil horizons : contribution and importance to soil carbon pools and in assessing whole-ecosystem response. Management and Global Change. 2011;57(1):67-76.

34. Vaidya S. Carbon stock estimation of the leasehold forest (A study from the shaktikhor VDC of the Chitwan District, Nepal). Kathmandu. Nepal: Tribhuwan University; 2012 p. 55-61. 